\title{
fMRI investigations of left and right PFC contributions to episodic remembering
}

\author{
CAROL L. RAYE, MARCIA K. JOHNSON, KAREN J. MITCHELL, and SCOTT F. NOLDE \\ Princeton University, Princeton, New Jersey \\ and \\ MARK D'ESPOSITO \\ University of California, Berkeley, California
}

\begin{abstract}
We used functional magnetic resonance imaging (fMRI) to investigate the relation between left and right prefrontal cortex (PFC) and task complexity in episodic memory. In Experiments 1A, 1B, and 1C, left PFC activity (and, in Experiment 1C, right PFC as well) was greater for source identification than for old/new recognition, indicating that left PFC is likely to be recruited when specific features of episodic memories are considered. In Experiment 2, we found greater activity in PFC areas more medial or more ventral to those found in Experiments $1 \mathrm{~A}-1 \mathrm{C}$ in successive recognition relative to forcedchoice recognition, indicating that the regions of PFC recruited depend on the nature of the task complexity. Furthermore, Experiment 2 provided evidence consistent with the hypothesis that increased processing complexity may require interhemispheric interaction. In Experiments 1A, 1C, and 2, increased task complexity also increased activity in anterior cingulate (ACC), consistent with the idea that $\mathrm{ACC}$ interacts with $\mathrm{PFC}$ to control processing during remembering.
\end{abstract}

Episodic memories, in contrast to semantic memories or beliefs, are distinguished by features that specify the circumstances of encoding- that is, the source of the memory (the what, where, when, who, and other features that make up an "event"). The source monitoring framework (SMF) characterizes the processes involved in encoding and remembering episodic memories (Johnson, Hashtroudi, \& Lindsay, 1993; Johnson \& Raye, 1981, 2000; Mitchell \& Johnson, 2000). Of particular relevance here are the subprocesses of remembering. The SMF proposes that remembering is not simply a matter of whether a representation is retrieved in response to a cue; remembering also involves attributing phenomenal experience to memory. These attributions involve evaluating the qualitative features of information activated by retrieval cues in the context of current goals and knowledge about the distinguishing characteristics of memories relevant to that goal. Current goals, such as a goal to identify something previously seen versus a goal to identify something previously heard, may modulate (bias) what information (e.g., visual information) is initially looked for or activated by a cue or how different features (e.g., visual vs. auditory) are weighted in making memory attributions (e.g., Johnson, Kounios, \& Nolde, 1996; Johnson et al., 1997;

This research was supported by NIA Grants AG09253 and AG15793, NSF Grant SBR98-71186, and Pew Charitable Trusts Grant 97001533-000. The authors would like to acknowledge the work of Erich Greene in fMRI data preparation and analysis, and thank Leigh Nystrom and Fred Sabb for software support and consultation. Correspondence should be addressed to C. L. Raye, Department of Psychology, Princeton University, Princeton, NJ 08544-1010 (e-mail: clr@princeton.edu).
Marsh \& Hicks, 1998). According to the SMF, retrieval and evaluation processes can be heuristic (relatively fast, effortless, and/or based on undifferentiated information) or more systematic (more deliberate, controlled or reflectively complex, and/or based on specific features). Retrieval and evaluation can be iterative, for example, requiring the self-generation of new cues (Johnson \& Raye, 1981, 2000; see also Burgess \& Shallice, 1996; Conway, 1992; Moscovitch, 1995; and Petrides, 1998, for similar multiple-process characterizations of remembering).

In general, retrieval and evaluation processes appear to be mediated by prefrontal cortex (PFC; Shallice et al., 1994; Tulving, Kapur, Craik, Moscovitch, \& Houle, 1994), presumably in interaction with other brain regions (e.g., Buckner, Kelley, \& Petersen, 1999; Goldman-Rakic, Selemon, \& Schwartz, 1984; Johnson, 1997). The relations between the component reflective processes involved in episodic remembering and particular PFC regions remain to be specified. For example, are different regions involved depending on whether episodic memory attributions are made more heuristically or systematically?

Nolde, Johnson, and Raye (1998) reviewed neuroimaging studies of episodic memory and found that both left and right PFC activity were more likely to be reported when the episodic memory task was more reflectively complex (involves more subprocesses or a more complex processing sequence), whereas only right PFC was likely to be reported for less complex memory tasks. For example, only right PFC activity typically was found in simple two-alternative forced-choice recognition (e.g., Moscovitch, Kapur, Köhler, \& Houle, 1995). In contrast, along with right activity, left PFC activity was sometimes 
found in old/new recognition where individual test items were successively presented for judgments (Tulving, Markowitsch, Craik, Habib, \& Houle, 1996). Forcedchoice recognition requires only a relative decision between the two items presented on each test trial. Making old/new recognition decisions to a series of items each presented singly may require more information and processes engaged to maintain a consistent criterion across items (e.g., reactivating other recent items). Furthermore, studies directly comparing difficult recognition with relatively easy recognition (e.g., items poorly encoded at study vs. items deeply encoded at study; Buckner, Koutstaal, Schacter, Wagner, \& Rosen, 1998) or difficult cued recall with relatively easy cued recall (e.g., low-associate or unrelated cues vs. high-associate cues; Fletcher, Shallice, Frith, Frackowiak, \& Dolan, 1996) have reported left and right $P F C$ activity in the more difficult task and almost exclusively right PFC activity in the easier task. Relative to easy cued recall, difficult cued recall, for example, is more likely to require repeated iterations of self-generated retrieval and evaluation and thus more component processes as well as greater control and integration of processing (e.g., more self-ordered behavior; Petrides, 1998).

On the basis of these and similar findings, Nolde, Johnson, and Raye (1998) proposed the cortical asymmetry of reflective activity (CARA) hypothesis - that heuristic processing is more likely to be subserved by right PFC and systematic processing is likely to recruit left PFC (see also Johnson, 1997; Johnson \& Raye, 1998). CARA fits with proposals and data about the relative roles of right and left hemispheres in other cognitive tasks. For example, there is some evidence that the right hemisphere subserves attention to more global visual aspects of a form and the left hemisphere subserves attention to local visual aspects (Robertson, 1995; Van Kleeck, 1989).

Another possibility that is not necessarily in conflict with CARA is a hemispheric interaction hypothesisthe idea that, relative to simple heuristic processing, more complex systematic processing is likely to require greater interhemispheric cooperation (e.g., Johnson \& Raye, 2000; see also Johnson, 1997, and Johnson \& Reeder, 1997). A related idea put forward by Banich (1998) is that each hemisphere may have different processing capabilities but that each can effectively allow processing to be shunted to the other when its processing capacity is being exceeded. The interaction hypothesis and CARA both emphasize the importance of both hemispheres in episodic remembering; CARA makes the additional proposal that systematic processes are especially likely to recruit left PFC.

Initially, both the hemispheric interaction and the CARA hypotheses may seem to conflict with the HERA model (hemispheric encoding/retrieval asymmetry; $\mathrm{Ny}$ berg, Cabeza, \& Tulving 1996; Tulving et al., 1994), which emphasizes the role of left PFC in episodic encoding and right $\mathrm{PFC}$ in episodic retrieval processes. However, recent work refining the HERA model has focused on the role of right PFC in establishing and maintaining a set to remember (retrieval mode; Lepage, Ghaffar, Nyberg, \& Tulving, 2000). The critical comparison in Lepage et al. is between tasks that require episodic remembering (e.g., old/new recognition) and tasks that do not (e.g., silent reading or semantic encoding). In contrast, the two hypotheses under present consideration propose differences in processing when a retrieval mode has been engaged and further processes of retrieval and evaluation are necessary. That is, to explore the hemispheric interaction or CARA hypothesis, critical comparisons include contrasts between episodic memory tasks that vary in retrieval and/or evaluation demands rather than between memory and nonmemory tasks.

To date, the evidence that most directly bears on the hypotheses under consideration contrasts episodic tasks that vary in the specificity of the information required. For example, in a study measuring event-related potentials (ERPs; Johnson et al., 1996), participants were shown pictures and words at study. At test, words were presented as probes, and old/new recognition (respond "yes" to any test word that represents an item from the study list and "no" to new items) was compared with a source identification test that required each test word to be identified as representing a previously studied picture, previously studied word, or a new item. Old/new recognition is often considered to be based on familiarity or recency, dimensions that are more global (less differentiated) than the more differentiated information required for the source test-for example, visual or auditory features (e.g., Jacoby, 1991; Johnson, Kounios, \& Reeder, 1994). Johnson et al. (1996) found that the source identification and old/new ERPs differed at frontal electrode sites (see also Ranganath \& Paller, 2000, and Senkfor \& Van Petten, 1998); however, localization of the source of ERPs is uncertain. A functional magnetic resonance imaging (fMRI) experiment using a similar design found greater left PFC activity in the source test than in the old/new test (Nolde, Johnson, \& D'Esposito, 1998; see also Ranganath \& Paller, 1999, for a similar left-lateralized finding with ERP).

In Experiments 1A, 1B, and 1C, we found further evidence that left PFC is more likely to be recruited in source identification compared to old/new recognition. In Experiment 2, we found a different pattern of PFC activation when successive old/new recognition was compared with forced-choice recognition. These results show that the left PFC areas associated with the episodic specificity of source tasks is not necessarily recruited by any increase in the complexity of a memory task.

The Institutional Review Boards at Princeton University and the University of Pennsylvania approved the experiments. All participants were healthy, right-handed young adults (mean age $=24.7$ years) from University of Pennsylvania or Princeton University. All were volunteers who gave written informed consent. There were 3 participants in Experiment 1A (1 female, 2 males), 3 in Experiment $1 \mathrm{~B}$ ( 3 females), 5 in Experiment $1 \mathrm{C}$ ( 2 females, 3 males), and 10 in Experiment 2 ( 4 females, 6 males). 


\section{EXPERIMENTS 1A, 1B, AND 1C}

At study, participants saw pictures and words and heard other words. Later, while they were scanned, participants performed one of three episodic tests on different blocks of trials. All three tests were successive tests that required "yes"/"no" responses. On old/new (O) blocks, participants were instructed to respond "yes" to old items regardless of the presentation format during study and "no" to new items. On picture (P) blocks, they were instructed to respond "yes" to any item presented as a picture at study and "no" to all other items (seen words, heard words, and new items). On picture/heard (PH) blocks, they were instructed to respond "yes" to any item presented as either a picture or a heard word at study and "no" to seen words and new items. Thus, we varied task complexity but held number of response alternatives constant. (In Nolde, Johnson, \& D'Esposito, 1998, the old/new test had two responses and the source test had three responses, leading to the possibility that the need for greater response selectivity drove the greater left PFC activation.)

The $\mathrm{PH}, \mathrm{P}$, and $\mathrm{O}$ conditions required three levels of specificity of featural information and corresponding control processes. Thus, we expected greatest left or bilateral PFC activation in the PH condition and least in the $\mathrm{O}$ condition. Because targets in the $\mathrm{PH}$ and $\mathrm{P}$ conditions differed from nontargets in their visual and/or auditory perceptual features, it would be hard to argue that greater left PFC activation in these conditions reflected greater verbal semantic processing (e.g., Andreasen et al., 1995).

\section{Method}

Materials. A set of 180 items were selected from the Snodgrass and Vanderwart (1980) norms; all items represented common objects (e.g., tiger, sandwich, sweater). Forty-five items were assigned to each of three sources: picture (black-and-white line drawings), heard word, and printed word. Forty-five items served as new items on the test list. Assignment of item to presentation type was random, with the constraints that the types were equated on average item familiarity, complexity, and image/name agreement as defined by the norms, as well as on category representation (e.g., animals). The three item types were randomly intermixed on the study list.

Acquisition procedure. Study items were presented one at a time by computer. On each study trial, a fixation cross hair was presented for $500 \mathrm{msec}$, followed by a picture (line drawing) or printed word shown in the center of the screen for $2 \mathrm{sec}$ or by a computerized replay of a spoken word about $1 \mathrm{sec}$ in duration. A new study item was presented every $5 \mathrm{sec}$. The participants were asked to rate the difficulty of drawing each acquisition item on a scale of 1 (easy) to 3 (difficult). For pictures, they were asked to base their rating on the presented drawing. For items presented as heard or printed words, they were asked to first form an image of the object represented by the word and base their drawing-difficulty rating on their image. Ratings were entered by pressing the appropriate key on a numberkey pad. This orienting task was selected to roughly equate old/new recognition of pictures and words (Durso \& Johnson, 1980) and to be consistent with earlier studies (Johnson et al., 1996; Nolde, Johnson, \& D'Esposito, 1998). The participants were given a short break halfway through the acquisition list. They were not told that there would be a later memory test.
Test procedure. The interval between acquisition and test was approximately $\mathbf{4 5} \mathrm{min}$, during which further test instructions were given, the participants were placed in the scanner, and structural images were acquired. Within a test block, test items (probes) from each of four potential sources (seen word, heard word, picture, new) were presented in random order. All probes were presented as printed words, projected by computer on a screen that the participants viewed in a mirror mounted on the head coil. Each test word was presented for $2 \mathrm{sec}$, and the participants'. responses were recorded anytime after the probe onset up until $2 \mathrm{sec}$ after its offset. A new test probe was presented every $16 \mathrm{sec}$ in Experiment $1 \mathrm{~A}$ and every $4 \mathrm{sec}$ in Experiments $1 \mathrm{~B}$ and $1 \mathrm{C}$. Test trials were presented in nine blocks of 20 trials each. For each block, the participants were given one of three test instructions corresponding to the three experimental conditions: $\mathrm{O}, \mathrm{P}$, and $\mathrm{PH}$. In all conditions, responses were made by pressing one of two buttons with the index finger ("yes" to targets) and the middle finger ("no" to nontargets) of the right hand. The participants were asked to respond as quickly but as accurately as possible. In all studies, each participant received a different ordering of the test conditions $(\mathrm{O}, \mathrm{P}, \mathrm{PH})$; for any given participant, a condition was not repeated before all three conditions had been presented.

fMRI procedure and data analysis. A 1.5T SIGNA scanner (GE Medical Systems) was used at the University of Pennsylvania Medical Center (Experiment 1A) and at Princeton Radiology Associates (Experiment $1 \mathrm{~B}$ and $\mathrm{IC}$ ). T1-weighted anatomical images were acquired for each participant. In Experiment 1A, a gradient echo, echoplanar pulse sequence, $\mathrm{TR}=2,000 \mathrm{msec}, \mathrm{TE}=50 \mathrm{msec}$, was used; 1,440 volumes of functional data per person were acquired, with 21 axial slices (resolution $3.75 \times 3.75 \mathrm{~mm}$ in plane, $5 \mathrm{~mm}$ between planes) in each volume. In Experiments $1 \mathrm{~B}$ and $1 \mathrm{C}$, a gradient echo, spiral pulse sequence was used (Noll, Cohen, Meyer, $\&$ Schneider, 1995), TR $=2,000 \mathrm{msec}, \mathrm{TE}=35 \mathrm{msec} ; 360$ volumes of functional data per person were acquired, with 20 axial slices (resolution $3.75 \times 3.75 \mathrm{~mm}$ in plane, $3.8 \mathrm{~mm}$ between planes) in each volume. Experiments $1 \mathrm{~B}$ and $1 \mathrm{C}$ differed in that the functional slices began 3 slices $(11.4 \mathrm{~mm})$ lower in Experiment $1 \mathrm{C}$ than in Experiment $1 \mathrm{~B}$ to increase orbital frontal coverage. Data were analyzed separately for each experiment.

After reconstruction, for all experiments, images were corrected for distortion, and time series were shifted by sync interpolation to correct for the interleaved slice acquisition sequence. Data were motioncorrected using a 6-parameter automated algorithm (AIR; Woods, Cherry, \& Mazziotta, 1992). In each experiment, a 12-parameter AIR algorithm was used to co-register the participants' images to a common reference brain chosen from that group. Data were meannormalized across time and participants and were spatially smoothed (using a three-dimensional, 8-mm full width-half maximum Gaussian kernel). The data from each study were analyzed using NIS software (developed by the Laboratory for Clinical Cognitive Neuroscience, University of Pittsburgh, and the Neuroscience of Cognitive Control Laboratory, Princeton University). In all analyses, participant was a random factor. Regions forward of the central sulcus were identified that had a minimum of 5 (Experiment $1 \mathrm{~B})$ or $6(\mathrm{Ex}-$ periment $1 \mathrm{~A}$ and $1 \mathrm{C}$ ) contiguous voxels, each voxel with a $t$ value significant at $p<.01$ (Forman et al., 1995). The coordinates reported in the tables represent local maxima in each region of activation that met this criterion. In Experiments $1 \mathrm{~A}$ and $\mathrm{IB}$, we used a monotonic linear contrast ordered PH $>$ P $>$ O (Braver \& Sheets, 1993) to identify areas consistent with our primary hypothesis. In Experiment 1C, we used planned contrasts in both directions among the three test conditions to identify regions that were either consistent or inconsistent with the experimental hypotheses. After data analysis, each set of group data was transformed to Talairach space, and areas of activation were localized using the AFNI software (Cox, 1996) and Talairach Daemon software (Lancaster, Summerlin, Rainey, Freitas, \& Fox, 1998) for UNIX, as well as manually checked against Talairach and Tournoux (1988). 


\section{Results}

Behavioral results. For each participant, in each condition, the proportion of hits (correct "yes" responses) and the proportion of false alarms (incorrect "yes" responses) were calculated and $d^{\prime}$ scores were obtained as an index of accuracy. The $d^{\prime}$ scores reflected the expected differences in accuracy among the conditions: In Experiment $1 \mathrm{~A}$, the mean $d^{\prime}$ scores for $\mathrm{O}, \mathrm{P}$, and $\mathrm{PH}$, respectively, were $2.37,1.90$, and 1.23 ; the corresponding means for Experiment 1B were 2.52, 2.29, and 1.29; and, for Experiment 1C, they were 2.98, 2.06, and 1.49.

fMRI results. Tables 1 and 2 list all regions forward of the central sulcus that were identified. As can be seen in Tables 1 and 2, all experiments resulted in differences between remembering conditions in activity in left PFC. Experiment $1 \mathrm{C}$ showed differences between test conditions in right PFC as well; Experiments $1 \mathrm{~A}$ and $1 \mathrm{C}$ showed differences in anterior cingulate.

Left PFC. In Experiments $1 \mathrm{~A}$ and 1B, one area of activation was identified: a region of dorsal lateral left PFC near the intersection of BA 9, 10, and 46 (Experiment 1A), and a nearby, more anterior, area of left BA 10 (Experiment 1B). In Experiment 1C, several regions of left BA 9, 10 , and 46 emerged, showing greater activity in $\mathrm{PH}$ than in $\mathrm{O}(\mathrm{BA} 9 / 44,10 / 46), \mathrm{PH}>\mathrm{P}(\mathrm{BA} 9,10)$, and $\mathrm{P}>\mathrm{O}$ (bilateral BA 10). In addition, in Experiment 1C, there was one area of activation in left orbital frontal cortex, where $\mathrm{O}>\mathrm{P}(\mathrm{BA} 11)$.

Right PFC. In Experiment 1C, but not in Experiments 1A or 1B (nor in Nolde, Johnson, \& D'Esposito, 1998), regions of right $P F C$ were also sensitive to test conditions: $\mathrm{PH}>\mathrm{O}$ (BA 10), $\mathrm{PH}>\mathrm{P}$ (BA 9), and $\mathrm{P}>\mathrm{O}$ (the previously mentioned bilateral BA 10 , and BA 8 ). With the exception of BA 8, each of these areas corresponds to an area of left activation in Experiment $1 \mathrm{C}$. There also was one area of right $\mathrm{PFC}$ (BA 10) where $\mathrm{O}>\mathrm{P}$. The only other region of frontal cortex that was significant in these comparisons was an area of right $\mathrm{BA} 6(\mathrm{PH}>\mathrm{O})$.

Table 1

Frontal Regions With a Minimum of Six (Experiment 1A) or Five (Experiment 1B) Contiguous Voxels, Each Significant at $p<.01(d f=2)$ in a Monotonic Linear Contrast $(\mathbf{P H}>\mathbf{P}>\mathbf{O})$.

\begin{tabular}{|c|c|c|c|c|c|c|}
\hline Hemisphere & Region & $\begin{array}{c}\text { Brodmann } \\
\text { Area }\end{array}$ & $x$ & $y$ & $z$ & $\begin{array}{c}\text { Maximum } \\
t \text { Value }\end{array}$ \\
\hline \multicolumn{7}{|c|}{ Experiment $1 \mathrm{~A}$} \\
\hline Left & $\mathrm{GFm}$ & $9 / 10 / 46$ & -23 & 38 & 21 & 25.27 \\
\hline Medial & Cing & 32 & 4 & 39 & 10 & $13.32^{*}$ \\
\hline Medial & Cing & 32 & 5 & 36 & 25 & $29.75^{*}$ \\
\hline Medial & Cing & 32 & 4 & 25 & 38 & 19.09 \\
\hline \multicolumn{7}{|c|}{ Experiment $1 \mathrm{~B}$} \\
\hline Left & GFs & 10 & -15 & 57 & 15 & 20.47 \\
\hline
\end{tabular}

Note-PH $=$ picture/heard (say "yes" to items studied as pictures or heard words); $\mathrm{P}=$ picture (say "yes" only to items studied as pictures); $\mathrm{O}=\mathrm{old} /$ new recognition (say "yes" to any old item); GFs, GFm, GFi, and GFd = superior, middle, inferior, and medial frontal gyrus, respectively; Cing = cingulate gyrus. ${ }^{*}$ Multiple local maxima in one continuous region of activation.
Anterior cingulate cortex. In Experiment 1A, there were two regions of activation in anterior cingulate (BA 32): one more inferior and one more superior. The more inferior region had two distinct local maxima, which we will refer to as inferior and middle; both are listed in Table 1 . In Experiment 1C, there were two ACC regions (BA 32), both $\mathrm{PH}>\mathrm{P}$; these coincide with the inferior and middle ACC regions in Experiment $1 \mathrm{~A}$.

\section{Discussion}

As shown in Figure 1, in four experiments (Nolde, Johnson, \& D'Esposito, 1998, Figure 1a, and the present Experiments $1 \mathrm{~A}, 1 \mathrm{~B}$, and $1 \mathrm{C}$, Figure $1 \mathrm{~b}$ ), we found increased left $P F C$ activity with increasing reflective demandsthat is, with increased requirements for considering specific features in episodic remembering (source identification vs. old/new recognition). In Experiment 1C, we also found similar areas of increased right PFC activity as the reflective demands of the task were increased. In no case did we find increased activity only in right PFC.

ACC activation is frequently reported in episodic memory tasks (e.g., Buckner, Raichle, Miezin, \& Petersen, 1996; Haxby, Ungerleider, Horwitz, Rapoport, \& Grady, 1995). For example, we examined the papers reviewed in Nolde, Johnson, and Raye (1998, Tables 1 and 2) and found that all but a few reported ACC activation in at least one episodic memory condition (see also Lepage et al., 2000). The present results (Experiments $1 \mathrm{~A}$ and $1 \mathrm{C}$ ) suggest that amount of ACC activity is related to variations in the task demands associated with episodic remembering.

In Experiments $1 \mathrm{~A}$ and $1 \mathrm{C}$, there were two common areas of anterior cingulate (the above mentioned inferior and middle activations) with greater activation in the $\mathrm{PH}$ condition and a third superior area in Experiment $1 \mathrm{~A}$. The superior ACC activation was near areas reported in Barch et al. (1997) and Carter et al. (1998). Carter et al. suggested that $\mathrm{ACC}$ is sensitive to response competition (see also Botvinick, Braver, Carter, Barch, \& Cohen, 1999). Activations near both our inferior ACC and superior ACC were reported in D'Esposito et al. (1995). They found greater ACC activity in these two areas during dual tasks than during single tasks and suggested that ACC is involved in task switching. One possibility is that both ideas are correct and that different regions of $\mathrm{ACC}$ participate in different but related functions (cf. Paus, Koski, Caramanos, \& Westbury, 1998). While the PFC is likely responsible for task control (e.g., Stuss \& Benson, 1986), the inferior ACC region may respond to competition or conflict between tasks - for example, competition that arises with simultaneous monitoring for either of two types of information, such as pictorial and auditory features during remembering. The superior $\mathrm{ACC}$ region may be sensitive to relations or conflict among representations or reflect uncertainty (see also Klingberg, O'Sullivan \& Roland, 1997). If the output of ACC regions reflects conflict or uncertainty, it might function to modulate further PFC processing (e.g., retrieval) or a change in 
Table 2

Frontal Regions in Experiment 1C With a Minimum of Six Contiguous Voxels, Each Significant at $p<.01(d f=4)$ in Pairwise $t$ Tests Between Conditions

\begin{tabular}{|c|c|c|c|c|c|c|c|}
\hline Contrast & Hemisphere & Region & $\begin{array}{c}\text { Brodmann } \\
\text { Area }\end{array}$ & $x$ & $y$ & $z$ & $\begin{array}{c}\text { Maximum } \\
t \text { Value }\end{array}$ \\
\hline $\mathrm{PH}>\mathrm{O}$ & Left & $\mathrm{GFm} / \mathrm{GFi}$ & $9 / 44$ & -45 & 20 & 29 & 9.86 \\
\hline $\mathrm{PH}>\mathrm{O}$ & Left & GFm & $10 / 46$ & -37 & 40 & 16 & 5.77 \\
\hline $\mathrm{PH}>\mathrm{P}$ & Left & GFm & 9 & -48 & 8 & 35 & 9.14 \\
\hline $\mathrm{PH}>\mathrm{P}$ & Left & $\mathrm{GFs} / \mathrm{GFm}$ & 10 & -27 & 60 & 24 & 12.61 \\
\hline $\mathrm{P}>\mathrm{O}$ & Bilateral & GFd, GFs & 10 & \pm 9 & 64 & -4 & 13.78 \\
\hline$O>P$ & Left & $\mathrm{GFm} / \mathrm{GOb}$ & 11 & -35 & 45 & -10 & 6.24 \\
\hline $\mathrm{PH}>\mathrm{O}$ & Right & GFs & 10 & 20 & 61 & 16 & 10.73 \\
\hline $\mathrm{PH}>\mathrm{P}$ & Right & GFm & 9 & 44 & 33 & 37 & 7.62 \\
\hline $\mathrm{PH}>\mathrm{P}$ & Right & GFm & 9 & 47 & 7 & 35 & 8.86 \\
\hline $\mathrm{PH}>\mathrm{O}$ & Right & GFm & 6 & 42 & 5 & 45 & 7.30 \\
\hline $\mathrm{P}>\mathrm{O}$ & Medial & GFd & 8 & 3 & 20 & 46 & 5.29 \\
\hline $\mathrm{O}>\mathrm{P}$ & Right & GFs & 10 & 22 & 53 & 12 & 10.33 \\
\hline $\mathrm{PH}>\mathrm{P}$ & Left & Cing & 32 & -8 & 40 & 10 & 7.74 \\
\hline $\mathrm{PH}>\mathrm{P}$ & Right & Cing & 32 & 8 & 36 & 23 & 6.17 \\
\hline
\end{tabular}

Note--PH = picture/heard (say "yes" to items studied as pictures or heard words); $\mathrm{P}=$ picture (say "yes" only to items studied as pictures); $\mathrm{O}=$ old/new recognition (say "yes" to any old item); GFs, GFm, GFi, and GFd = superior, middle, inferior, and medial frontal gyrus, respectively; $\mathrm{GOb}=$ orbital gyrus; $\mathrm{Cing}=$ cingulate gyrus.

processing (e.g., a need to adjust criteria). In other words, regions of ACC and PFC may interact during normal retrieval and monitoring of episodic memories (as well as in other tasks; Botvinick et al., 1999). In any event, the fact that damage to PFC and ACC can both produce deficits in source memory provides converging evidence that these regions are critical for normal memory function (see Johnson, Hayes, D'Esposito, \& Raye, 2000 , for a review of related neuropsychological studies of confabulation).

\section{EXPERIMENT 2}

In Experiment 2, we varied the reflective complexity of the episodic memory task by comparing two-alternative forced-choice recognition and successive old/new recognition. In forced-choice recognition, the test probe was a

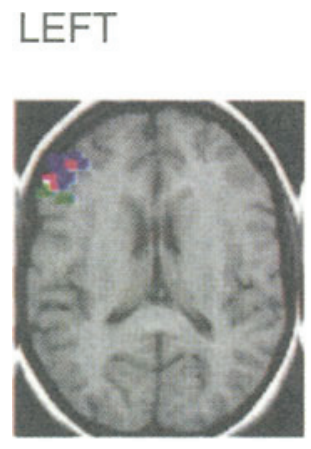

(a)

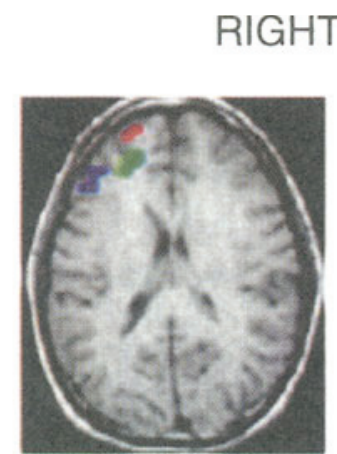

(b)
Figure 1. (a) PFC activation from Nolde, Johnson, and D'Esposito (1998) (note that each color represents a different one of 3 participants who showed greater left activation in a source monitoring task than in old/new recognition); (b) frontal activations from the present Experiments $1 \mathrm{~A}$ (green ), $1 \mathrm{~B}$ (red), and $1 \mathrm{C}$ (blue). pair of items, one old and one new, and the participant was asked to select the old item in each test pair. In successive recognition, old and new items were randomly intermixed and presented one at a time, and participants indicated "yes" (old) or "no" (new) to each item. It is generally assumed that forced-choice recognition is a simpler task than successive recognition (e.g., Macmillan \& Creelman, 1991). As noted in the introduction, forcedchoice recognition decisions can be based on the difference in familiarity of the members of each test pair. In successive recognition, participants must develop and maintain a criterion across trials and, on average, greater familiarity should be required than is required for relative judgments. Relative to forced-choice recognition, successive recognition may also be more likely to sometimes involve the revival of specific information (or "recollection"; e.g., Jacoby, 1991), although less than in the case of source identification (e.g, as investigated in Experiments 1A, 1B, and 1C).

The literature reviewed in Nolde, Johnson, and Raye (1998) showed that studies using forced-choice recognition tended to report only right PFC activation and studies using successive recognition tended to report left and right PFC activation (see Tables 1 and 2 in Nolde, Johnson, \& Raye, 1998). However, comparing across studies runs risks of uncontrolled variables, the most obvious of which is that the studies using the forced-choice procedure tended to involve pictorial materials, whereas the studies using the successive procedure tended to involve verbal materials. Thus, in Experiment 2, we contrasted forcedchoice and successive recognition for non-nameable textures and for words. Previous results suggest that, to some extent, activation in PFC during episodic remembering is lateralized by materials - with greater right PFC activity in textures than in words and greater left PFC activity in words than in textures (Wagner et al., 1998). Here, we were primarily interested in PFC activity over and above 
that attributable to stimulus materials per se- that is, activity that arose as processing demands of the task were increased from forced choice to successive recognition. If the left PFC activity found in Experiments 1A, 1B, and $1 \mathrm{C}$ reflects a general response to task complexity, then we would expect increased left PFC activity in the successive condition for both textures and words. In contrast, if the left PFC activity found in Experiments 1A, $1 \mathrm{~B}$, and $1 \mathrm{C}$ is related to the episodic specificity required by source monitoring, we would not necessarily expect increased reflective complexity in Experiment 2 to activate the same $\mathrm{PFC}$ regions that were more active in the source tasks in Experiments 1A, 1B, and 1C. Experiment 2 also allowed us to explore neural activity related to processing demands over and above that related to differences in processing associated with materials. According to the hemispheric interaction hypothesis, we might expect increased activity in the hemisphere contralateral to that involved in any materials effect if the increased demands are sufficient to engage hemispheric cooperation.

\section{Method}

Materials. Two 144-item study lists each contained 72 textures (T) and 72 abstract words (W), 142 of each from Wagner et al. (1998). Each study list was composed of four 36-trial alternating blocks of T and of W items (order TWTW or WTWT). The participants were randomly assigned to study list and block order. The nonstudied list served as distractors at test.

Acquisition procedure. The participants studied items during the final structural scan and were told to try to remember each study item for a later memory test. Stimuli were projected as described for Experiments 1A, 1B, and 1C. Each study item was presented for $1,500 \mathrm{msec}$, followed by a 700 -msec interstimulus interval (ISI). To maximize the visibility of the textures, all stimuli were presented on a pale cyan background.

Test procedure. The test consisted of sixteen 12-trial blocks, 4 blocks of each type of test: two-alternative forced-choice textures (FC-T), two-alternative forced-choice words (FC-W), successive recognition textures (S-T), successive recognition words (S-W). For forced-choice trials, an old item and a new item were presented simultaneously, one item to the right and the other to the left (position of old and new items was randomly assigned). Using two fingers of the right hand, the participants pressed the right or left response button according to the position of the item they believed was old. For successive trials, a single item was presented in the center of the screen, and the participants pressed the right button if they thought it was old and the left if they thought it was new. In all cases, the participants were told to respond as quickly as possible without sacrificing accuracy. Test trials were presented in four cycles, each cycle contained one block of each of the four test types in random order; $6 \mathrm{sec}$ of blank screen separated the blocks of trials. On each test trial, the stimulus display was on for $2 \mathrm{sec}$, followed by a $2-\mathrm{sec}$ ISI, during which time the screen was blank.

fMRI prodedure and data analysis. Twenty-four volumes were collected per test condition in each cycle, for a total of 96 volumes per test condition, per participant. Data were acquired at Princeton Radiology Associates with parameters and pulse sequence identical to those described above for Experiment 1C. Data preparation and analysis were as described above. Planned contrasts identified regions of significant differential activation that had at least 10 contiguous voxels, each voxel with a $t$ value significant at $p<.01$.

\section{Results}

Behavioral data. Because of a technical failure, behavioral data were not recorded for 1 of the 10 participants. The mean corrected recognition scores (proportion hits minus proportion false alarms) were as follows: FC-T, .46; FC-W, .40; S-T, .21; and S-W, .37. A 2 (test type) $\times$ 2 (materials) analysis of variance indicated that the participants did significantly worse on the successive tests $(M=0.29, S D=0.13)$ than on the forced-choice tests $(M=0.43, S D=0.16)\left[F(1,8)=34.51, M S_{\mathrm{e}}=0.01\right.$, $p<.001]$. There was also a test $\times$ material type interaction $\left[F(1,8)=5.18, M S_{\mathrm{e}}=0.02, p=.05\right)$. Post hoc $t$ tests showed that improvement on the forced-choice test over the successive test was greater for textures $[t(8)=4.83$, $p=.001]$ than for words $(t<1)$.

fMRI data. As can be seen in Table 3, direct successive $>$ forced-choice contrasts yielded medial BA 9, 10 regions for both textures and words. In addition, for both types of materials, there were ventral lateral regions where successive > forced-choice, most notably, left BA 44, 45 for textures and left and right BA 44 for words. Thus, $P F C$ regions that were responsive to the processing differences between successive and forced-choice recognition tended to be more medial (BA 9, 10) and ventral (BA 44,45 ) than those responsive to the processing differences between old/new recognition and source identification (BA 9, 10, 46).

Also, Experiment 2 findings were consistent with the findings of Experiments $1 \mathrm{~A}$ and $1 \mathrm{C}$ in showing greater ACC (BA 32, 24 for both textures and words) activity associated with more reflectively demanding tasks (see also Mitchell, Johnson, Raye, \& D'Esposito, in press). Notably, there was overlap between the ACC areas found in successive $>$ forced choice for Experiment 2 and the inferior ACC region found in Experiments $1 \mathrm{~A}$ and $1 \mathrm{C}$ and found in D'Esposito et al. (1995). It can be argued that all of these have some type of dual processing relative to their respective controls-for example, monitoring for two features or maintaining a criterion by reflecting on earlier items while evaluating a current item.

Finally, in the forced-choice condition, the textures $>$ words ( $\mathrm{T}>\mathrm{W}$ ) contrast showed right $\mathrm{PFC}$ activity whereas the $\mathrm{W}>\mathrm{T}$ contrast showed left PFC activity, consistent with other evidence of laterality effects associated with materials (e.g., Wagner et al., 1998). However, of more interest here, when the same contrasts were examined in the successive condition, activity was found in both left and right $\mathrm{PFC}$ regions for both $\mathrm{T}>\mathrm{W}$ and $\mathrm{W}>\mathrm{T}$. That is, the more difficult successive test recruited PFC activation not only in the hemisphere usually associated with that type of material but also in the opposite hemisphere.

\section{GENERAL DISCUSSION}

In contrast to an undifferentiated feeling of familiarity, what makes a memory "episodic" is that it has specific features. Experiments 1A, 1B, and 1C showed that 
Table 3

Frontal Regions in Experiment 2 With a Minimum of 10 Contiguous Voxels,

Each Significant at $p<.01(d f=9)$ in Pairwise $t$ Tests Between Conditions

\begin{tabular}{|c|c|c|c|c|c|c|c|}
\hline Contrast & Hemisphere & Region & $\begin{array}{c}\text { Brodmann } \\
\text { Area }\end{array}$ & $x$ & $y$ & $z$ & $\begin{array}{c}\text { Maximum } \\
t \text { Value }\end{array}$ \\
\hline \multirow[t]{7}{*}{$\mathrm{S}>\mathrm{FC}$ in $\mathrm{T}$} & Medial & GFd, GFs & $10(9)$ & 6 & 63 & 16 & $7.50^{*}$ \\
\hline & Medial & Cing & $32(24)$ & 6 & 38 & 21 & $5.68^{*}$ \\
\hline & Bilateral & Cing, GFm, GFd & 32,11 & \pm 11 & 29 & -8 & $5.38^{*}$ \\
\hline & Bilateral & Cing & 32 & \pm 10 & 32 & 34 & 5.45 \\
\hline & Left & $\mathrm{GFi}$ & 44,45 & -46 & 16 & 14 & 5.80 \\
\hline & Left & $\mathrm{GFs} / \mathrm{GFm}$ & 8 & 22 & 32 & 40 & 6.62 \\
\hline & Right & GprC & 6 & 45 & 1 & 4 & 3.56 \\
\hline \multirow[t]{6}{*}{$\mathrm{S}>\mathrm{FC}$ in $\mathrm{W}$} & Medial and Right & $\mathrm{GFs} / \mathrm{GFd}$ & 10,9 & 10 & 60 & 26 & 3.64 \\
\hline & Medial & Cing & 32,24 & -3 & 17 & 31 & 4.29 \\
\hline & Medial & Cing & 32,24 & 3 & 35 & 11 & 3.44 \\
\hline & Left & GPrC, GFi & 6,44 & -55 & 4 & 26 & 4.34 \\
\hline & Right & GFi & 44 & 56 & 10 & 16 & 4.91 \\
\hline & Right & GFm & 9,8 & 31 & 40 & 36 & 7.7 \\
\hline $\mathrm{T}>\mathrm{W}$ in $\mathrm{FC}$ & Right & GFi, GFm & $47 / 11$ & 32 & 33 & -2 & 4.81 \\
\hline \multirow[t]{4}{*}{$\mathrm{W}>\mathrm{T}$ in $\mathrm{FC}$} & Left & GFi & $45,46(44,47)$ & -45 & 18 & 8 & $7.88^{*}$ \\
\hline & Left & GFm/GFi & $9,45,46$ & -41 & 22 & 22 & $8.27^{*}$ \\
\hline & Left & GFm & 8 & -33 & 12 & 40 & $7.02^{*}$ \\
\hline & Medial & GFd, GFs & 8,9 & -2 & 43 & 37 & 3.74 \\
\hline \multirow[t]{2}{*}{$\mathrm{T}>\mathrm{W}$ in $\mathrm{S}$} & Left & GFd/Cing, GFi & $10,32,47$ & -18 & 43 & -4 & 3.91 \\
\hline & Right & $\mathrm{GFi} / \mathrm{GOb}$ & $47 / 11$ & 24 & 34 & -8 & 5.55 \\
\hline \multirow[t]{4}{*}{$\mathrm{W}>\mathrm{T}$ in $\mathrm{S}$} & Left & $\mathrm{GFm} / \mathrm{GFi}$ & $9,45,46(8 / 9,44)$ & -45 & 26 & 20 & $8.66^{*}$ \\
\hline & Left & $\mathrm{GFi} /$ ins & $47 /$ ins & -37 & 20 & 0 & $6.16^{*}$ \\
\hline & Right & $\mathrm{GFm} / \mathrm{GFi}$ & $10,9,46$ & 34 & 43 & 20 & 6.16 \\
\hline & Right & ins/GFi & ins $/ 45$ & 37 & 14 & 12 & 4.32 \\
\hline
\end{tabular}

Note-BA areas in parentheses were included in the area of activation, but were not local maxima. $S=$ successive yes/no recognition test; $\mathrm{FC}=$ forced-choice test; $\mathrm{T}=$ textures; $\mathrm{W}=$ words; GFs, GFm, GFi, and GFd = superior, middle, inferior, and medial frontal gyrus, respectively; Cing, GOb = cingulate, orbital gyrus, respectively; ins = insula. $\quad$ *Multiple local maxima in one continuous region of activation.

increased demands to consider the features of phenomenal experience (source identification vs. old/new recognition) resulted in increased activity in left PFC extending the findings reported by Nolde, Johnson, and D'Esposito (1998). Similar evidence comes from other recent source monitoring studies investigating the location or list membership of words (Henson, Shallice, \& Dolan, 1999; Rugg, Fletcher, Chua, \& Dolan, 1999) or the size of pictures (Ranganath, Johnson, \& D'Esposito, 2000). Figure 2 shows the left dorsal lateral and anterior regions of PFC activity (largely BA 9, 10,46) in these experiments (other PFC areas of activation that were less consistent across experiments are not shown). Thus, there is clear evidence that, as a memory task requires greater episodic specificity or consideration of more features, activity in left anterior and dorsal lateral PFC is likely to increase, presumably because of the increased reflective demands of looking for, reviving, and/or monitoring specific features in source discrimination, relative to old/new recognition. Right PFC activity sometimes increased in source tasks relative to old/new recognition (the present study 1C; Rugg et al., 1999); however, this effect was less reliable across experiments.

In Experiment 2, we compared a relatively simple twoalternative forced-choice recognition task with a more complex successive old/new recognition task for two

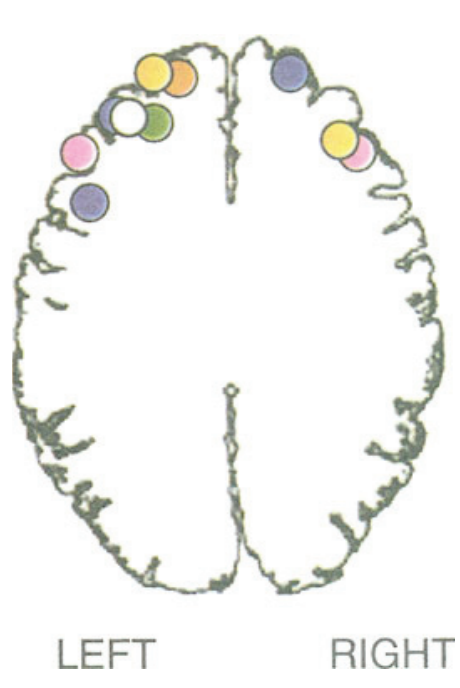

Figure 2. Frontal activations from: (green) the present Experiment 1A, (red) the present Experiment 1B, (blue) the present Experiment $1 \mathrm{C}(\mathrm{PH}-\mathrm{O})$, (white) Ranganath, Johnson, and D'Esposito (2000) $(x=-35, y=40, z=12)$, (gold) Rugg, Fletcher, Chua, and Dolan (1999) (source memory - high-density recognition: $x=-22, y=60, z=12$, and $x=42, y=34, z=18$, (pink) Henson, Shallice, and Dolan (1999) (exclusion - inclusion: $x=-48, y=30, z=27$, and $x=48, y=30, z=21$ ). Slice represents a $z$ dimension of $12-29$. 
types of materials: textures and words. The difference in PFC activity in the successive $>$ forced-choice comparisons was in areas that were more medial or more ventral than those found in Experiments 1 A, 1B, and 1C. Medial and ventral PFC areas may help bridge the gap across successive trials. For example, they may contribute to the control and maintenance associated with modulating a criterion. Source identification presumably involves such processes as well. However, in addition, it involves attention to or evaluation of specific featural information (i.e., more differentiated qualities of memories); more dorsal areas of PFC, especially left PFC, are recruited for these cognitive operations. Thus, across Experiments 1A, 1B, 1C, and 2, we see apparent dissociation of function between anterior and dorsal versus medial and ventral PFC (cf. D'Esposito et al., 1998; Petrides, 1998).

Finally, Experiment 2 showed that, in forced-choice recognition, PFC activation was strongly lateralized in the $\mathrm{T}>\mathrm{W}$ (right) and $\mathrm{W}>\mathrm{T}$ (left) contrasts, but, in the successive condition, there was activity in both right and left PFC in both $\mathrm{T}>\mathrm{W}$ and $\mathrm{W}>\mathrm{T}$ contrasts (see also Wagner et al., 1998). This pattern suggests that the increased reflective demands of the successive test increased activity in the hemisphere opposite of that associated with materials effects (right for textures, left for words), as well as in the modality-congruent hemisphere, providing evidence consistent with the hemispheric interaction hypothesis (Banich, 1998; Johnson \& Raye, 2000).

In short, in PFC, there are likely modality effects (pictorial, verbal) that are correlated with hemisphere (e.g., McDermott, Buckner, Petersen, Kelley, \& Sanders, 1999; Wagner et al., 1998; the present Experiment 2) and processing effects correlated with hemisphere (e.g., Nolde, Johnson, \& D'Esposito, 1998; Ranganath et al., 2000; Robertson, 1995; the present Experiments 1A and 1B). Nevertheless, there also appear to be mechanisms by which reflective operations are distributed and coordinated across the hemispheres (e.g., the present Experiment 2) as task demands increase (Banich, 1998; Johnson \& Raye, 2000).

According to the SMF, the cognitive processes involved in episodic remembering are not solely dedicated to episodic remembering. Rather, they are recruited from a set of more generally useful component cognitive processes (e.g., as outlined in MEM; Johnson, 1992, 1997). Along these lines, it is interesting to note that a perceptual attention manipulation analogous to our comparison of $P$ and $\mathrm{PH}$ was investigated in a PET study by Vandenberghe et al. (1997). When Vandenberghe et al. compared monitoring for a single perceptual feature or two perceptual features of the same object, they found greater activation for the two-feature condition predominately in the left hemisphere, in BA 46/10. Also, in a delayed matching task using colored patterns, Klingberg et al. (1997) found left but not right PFC activity (BA 10,9) when participants were monitoring for changes in either of two features or switching between features relative to monitoring for completely new items. Taken together, these results suggest that the cognitive processes subserved by PFC regions are not specific to long-term episodic memory but are recruited in selective attention tasks and working memory as well. If so, it is unlikely that the left PFC activity in Figure 1 reflects the amount of feature information retrieved from long-term memory. Rather, it is more likely to reflect processes involved in looking for (biasing) or evaluating specific types of information.

Another intriguing question is, what is the role of the anterior cingulate in episodic memory? Increased task demands were associated with increased activity in ACC (BA 32) in Experiments 1A, 1C (see also Rugg et al., 1999), and 2. As discussed above, ACC, by interacting with PFC, may play a role in modulating and/or initiating reflective activity, and different areas of ACC may play different roles, such as detecting conflict between active representations or between tasks (see Botvinick et al., 1999; D'Esposito et al., 1995). More generally, the present findings fit with evidence obtained in neuroimaging studies of attention and working memory about the possible roles of PFC and anterior cingulate regions in manipulating and maintaining information, including task goals or context (Cohen, Braver, \& O'Reilly, 1996; D'Esposito et al., 1998; Smith \& Jonides, 1999) and monitoring conflict (Carter et al., 1998).

Episodic remembering is a function of a complex set of component cognitive processes that involve maintaining one or more task sets or agendas (including a set to remember), activation of information in response to explicit or implicit cues, maintaining activated information, evaluating information with respect to situational or longterm feature weights and criteria, initiating further memory retrieval, and so forth (e.g., Johnson, 1997; Johnson \& Raye, 2000). We would expect that the specific areas that are recruited within either hemisphere will depend on the cognitive processes required. The exact component reflective processes that need to be added in going from forced-choice to successive recognition are not likely to be exactly the same as those that need to be added in going from recognition to source identification. Thus, it is not surprising that the areas of PFC that showed increased activity with increased task complexity in Experiment 2 were not exactly the same as those in Experiments $1 \mathrm{~A}, 1 \mathrm{~B}$, and $1 \mathrm{C}$. Taken together then, these results suggest that increments in reflective processing complexity are likely to produce increases in PFC activity, but where the increased activity is seen depends on the level of involvement of each hemisphere in the "baseline" task and the specific cognitive processes required in the more complex task. Given what we know about the cognitive processes involved in remembering, hypotheses such as HERA (Tulving et al., 1994), CARA (Nolde, Johnson, \& Raye, 1998) or hemispheric interaction hypotheses (Banich, 1998; Johnson \& Raye, 2000) are really quite coarse. Systematic work varying task demands will be needed to specify the circuits of interaction among right and left PFC (including potentially different roles for anterior, dorsal lateral, ventral medial and orbital 
frontal cortex; e.g., Henson et al., 1999; Petrides, 1998; Rugg et al., 1999), anterior cingulate, and other brain regions that underlie various component cognitive processes engaged during episodic remembering (see Cummings, 1993; Johnson et al., 2000).

\section{REFERENCES}

Andreasen, N. C., O'Leary, D. S., Arndt, S., Cizadlo, T., Hurtig, R., Rezai, K., Watkins, G. L., Ponto, L. L. B., \& Hichwa, R. D. (1995). Short-term and long-term verbal memory: A positron emission tomography study. Proceedings of the National Academy of Sciences, 92, 5111-5115.

BANICH, M. T. (1998). The missing link: The role of interhemispheric interaction in attentional processing. Brain \& Cognition, 36, 128-157.

Barch, D. M., Braver, T. S., Nystrom, L. E., Forman, S. D., Noll, D. C., \& CoHEN, J. D. (1997). Dissociating working memory from task difficulty in human prefrontal cortex. Neuropsychologia, 35, 1373-1380

Botvinick, M. M., Braver, T. S., Carter, C. S., Barch, D. M., \& Conen, J. D. (1999). Evaluating the demand for control: Anterior cingulate cortex and crosstalk monitoring. Manuscript submitted for publication.

Braver, S. L., \& Sheets, V. L. (1993). Monotonic hypotheses in multiple group designs: A Monte Carlo study. Psychological Bulletin, 113, 379-395.

Buckner, R. L., Kelley, W. M., \& Petersen, S. E. (1999). Frontal cortex contributes to human memory formation. Nature Neuroscience, 2, 311-314.

Buckner, R. L., KoutstaAl, W., Schacter, D. L., Wagner, A. D., \& ROSEN, B. R. (1998). Functional-anatomic study of episodic retrieval using fMRI: 1. Retrieval effort versus retrieval success. Neurolmage, 7, 151-162.

Buckner, R. L., Raichle, M. E., Miezin, F. M., \& Petersen, S. E. (1996). Functional anatomic studies of memory retrieval for auditory words and visual pictures. Journal of Neuroscience, 16, 6219-6235.

Burgess, P. W., \& Shallice, T. (1996). Confabulation and the control of recollection. Memory, 4, 359-411.

Carter, C. S., Braver, T. S., Barch, D. M., Botvinick, M. M., Noll, D. C., \& COHEN, J. D. (1998). Anterior cingulate cortex, error detection and the on-line monitoring of performance. Science, 280, 747-749.

Cohen, J. D., Braver, T. S., \& O'Reilly, R. C. (1996). A computational approach to prefrontal cortex, cognitive control and schizophrenia: Recent developments and current challenges. Philosophical Transactions of the Royal Society of London: Series B, 351, 1515-1527.

ConwAY, M. A. (1992). A structural model of autobiographical memory. In M. A. Conway, D. C. Rubin, H. Spinnler, \& W. Wagenaar (Eds.), Theoretical perspectives on autobiographical memory (pp. 167-193). Boston: Kluwer

Cox, R. W. (1996). AFNI: Software for analysis and visualization of functional magnetic resonance neuroimages. Computers \& Biomedical Research, 29, 162-173.

Cummings, J. L. (1993). Frontal-subcortical circuits and human behavior. Archives of Neurology, 50, 873-880.

D'Esposito, M., Aguirre, G. K., Zarahn, E., Ballard, D., Shin, R. K., \& LEASE, J. (1998). Functional MRI studies of spatial and nonspatial working memory. Cognitive Brain Research, 7, 1-13.

D'Esposito, M., Detre, J. A., Alsop, D. C., Shin, R. K., Atlas, S., \& Grossman, M. (1995). The neural basis of the central executive system of working memory. Nature, 378, 279-281.

Durso, F. T., \& Johnson, M. K. (1980). The effects of orienting tasks on recognition, recall, and modality confusion of pictures and words. Journal of Verbal Learning \& Verbal Behavior, 19, 416-429.

Fletcher, P. C., Shallice, T., Frith, C. D., Frackowiak, R. S. J., \& Dolan, R. J. (1996). Brain activity during memory retrieval: The influence of imagery and semantic cueing. Brain, 119, 1587-1596.

Forman, S. D., Cohen, J. D., Fitzgerald, M., Eddy, W. F., Mintun, M. A., \& NoLL, D. C. (1995). Improved assessment of significant ac- tivation in functional magnetic resonance imaging ( $\mathrm{FMRI}$ ): Use of a cluster-size threshold. Magnetic Resonance in Medicine, 33, 636-647.

Goldman-Rakic, P. S., Selemon, L. D., \& Schwartz, M. L. (1984). Dual pathways connecting the dorsolateral prefrontal cortex with the hippocampal formation and parahippocampal cortex in the rhesus monkey. Neuroscience, 12, 719-743.

HAXBY, J. V., UNGERLEIDER, L. G., HoRWITZ, B., RAPOPORT, S. I., \& GRADY, C. L. (1995). Hemispheric differences in neural system for face working memory: A PET-rCBF study. Human Brain Mapping, 3, 68-82.

Henson, R. N. A., Shallice, T., \& Dolan, R. J. (1999). Right prefrontal cortex and episodic memory retrieval: A functional MRI test of the monitoring hypothesis. Brain, 122, 1367-1381.

JACOBY, L. L. (1991). A process dissociation framework: Separating automatic from intentional uses of memory. Journal of Memory \& Language, 30, 513-541.

JoHNSON, M. K. (1992). MEM: Mechanisms of recollection. Journal of Cognitive Neuroscience, 4, 268-280.

JOHNSON, M. K. (1997). Identifying the origin of mental experience. In M. S. Myslobodsky (Ed.), The mythomanias: The nature of deception and self-deception (pp. 133-180). Mahwah, NJ: Erlbaum.

Johnson, M. K., Hashtroudi, S., \& Lindsay, D. S. (1993). Source monitoring. Psychological Bulletin, 114, 3-28.

Johnson, M. K., Hayes, S. M., D'Esposito, M., \& Raye, C. L. (2000) Confabulation. In F. Boller \& J. Grafman (Eds.), Handbook of neuropyschology (2nd ed., Vol. 4, pp. 359-383). Amsterdam: Elsevier.

JoHnson, M. K., Kounios, J., \& NoldE, S. F. (1996). Electrophysiological brain activity and memory source monitoring. NeuroReport, 7, 2929-2932.

Johnson, M. K., Kounios, J., \& ReEder, J. A. (1994). Time-course studies of reality monitoring and recognition. Journal of Experimental Psychology: Learning, Memory, \& Cognition, 20, 1409-1419.

Johnson, M. K., Nolde, S. F., Mather, M., Kounios, J., Schacter, D. L., \& CURRAN, T. (1997). The similarity of brain activity associated with true and false recognition depends on test format. Psychological Science, 8, 250-257.

Johnson, M. K., \& RAYE, C. L. (1981). Reality monitoring. Psychological Review, 88, 67-85.

Johnson, M. K., \& RAYE, C. L. (1998). False memories and confabulation. Trends in Cognitive Sciences, 2, 137-145.

Johnson, M. K., \& RAYE, C. L. (2000). Cognitive and brain mechanisms of false memories and beliefs. In D. L. Schacter \& E. Scarry (Eds.), Memory and belief (pp. 35 - 86). Cambridge, MA: Harvard University Press.

Johnson, M. K., \& ReEder, J. A. (1997). Consciousness as metaprocessing. In J. D. Cohen \& J. W. Schooler (Eds.), Scientific approaches to consciousness (pp. 261-293). Mahwah, NJ: Erlbaum.

Klingberg, T., O’Sullivan, B. T., \& Roland, P. E. (1997). Bilateral activation of fronto-parietal networks by incrementing demand in a working memory task. Cerebral Cortex, 7, 465-471.

Lancaster, J. L., Summerlin, J. L., Rainey, L., Freitas, C. S., \& Fox, P. T. (1998). The Talairach Daemon, a database server for Talairach Atlas Labels. Neurolmage, 5 (4), S633.

Lepage, M., Ghaffar, O., Nyberg, L., \& Tulving, E. (2000). Prefrontal cortex and episodic memory retrieval mode. Proceedings of the National Academy of Sciences, 97, 506-511.

Macmillan, N. A., \& Creelman, C.D. (1991). Detection theory: A user's guide. New York: Cambridge University Press.

MARSH, R. L., \& Hicks, J. L. (1998). Test formats change sourcemonitoring decision processes. Journal of Experimental Psychology: Learning, Memory, \& Cognition, 24, 1137-1151.

McDermott, K. B., Buckner, R. L., Petersen, S. E., Kelley, W. M., \& SANDERS, A. L. (1999). Set- and code-specific activation in the frontal cortex: An fMRI study of encoding and retrieval of faces and words. Journal of Cognitive Neuroscience, 11, 631-640.

Mitchell, K. J., \& Johnson, M. K. (2000). Source monitoring: Attributing mental experiences. In E. Tulving \& F. I. M. Craik (Eds.), The Oxford handbook of memory (pp. 179-195). New York: Oxford University Press. 
Mitchell, K. J., Johnson, M. K., RAYE, C. L., \& D'Esposito, M. (in press). fMRI evidence of age-related hippocampal dysfunction in feature binding in working memory. Cognitive Brain Research.

Moscovitch, M. (1995). Confabulation. In D. L. Schacter (Ed.), Memory distortion: How minds, brains, and societies reconstruct the past (pp. 226-251). Cambridge, MA: Harvard University Press.

Moscovitch, M., Kapur, S., KöHLer, S., \& Houle, S. (1995). Distinct neural correlates of visual long-term memory for spatial location and object identity: A positron emission tomography study in humans. Proceedings of the National Academy of Sciences, 92, 3721-3725.

Nolde, S. F., Johnson, M. K., \& D'Esposito, M. (1998). Left prefrontal activation during episodic remembering: An event-related fMRI study. NeuroReport, 9, 3509-3514.

NoldE, S. F., Johnson, M. K., \& RAYE, C. L. (1998). The role of the prefrontal cortex during tests of episodic memory. Trends in Cognitive Sciences, 2, 399-406.

Noll, D. C., Cohen, J. D., Meyer, C. H., \& Schneider, W. (1995). Spiral K-space MR imaging of cortical activation. Journal of Magnetic Resonance Imaging, 5, 49-56.

Nyberg, L., Cabeza, R., \& Tulving, E. (1996). PET studies of encoding and retrieval: The HERA model. Psychonomic Bulletin \& Review, 3, 135-148.

Paus, T., Koski, L., Caramanos, Z., \& Westbury, C. (1998). Regional differences in the effects of task difficulty and motor output on blood flow response in the human anterior cingulate cortex: A review of 107 PET activation studies. NeuroReport, 9, R37-R47.

Petrides, M. (1998). Specialized systems for the processing of mnemonic information within the primate frontal cortex. In A. C. Roberts, T. W. Robbins, \& L. Weiskrantz (Eds.), The prefrontal cortex: Executive and cognitive functions (pp. 103-116). New York: Oxford University Press.

Ranganath, C., Johnson, M. K., \& D'Esposito, M. (2000). Left anterior prefrontal activation increases with demands to recall specific perceptual information. Manuscript submitted for publication.

Ranganath, C., \& Paller, K. A. (1999). Frontal brain potentials during recognition are modulated by requirements to retrieve perceptual detail. Neuron, 22, 605-613.

Ranganath, C., \& Paller, K. A. (2000). Neural correlates of memory retrieval and evaluation. Cognitive Brain Research, 9, 209-222.

RoBERTSON, L. C. (1995). Hemispheric specialization and cooperation in processing complex visual patterns. In F. L. Kitterle (Ed.), Hemispheric communication: Mechanisms and models (pp. 301-318). Hillsdale, NJ: Erlbaum.

Rugg, M. D., Fletcher, P. C., Chua, P. M.-L., \& Dolan, R. J. (1999).
The role of the prefrontal cortex in recognition memory and memory for source: An fMRI study. Neurolmage, 10, 520-529.

Senkfor, A. J., \& VAn Petren, C. (1998). Who said what? An eventrelated potential investigation of source and item memory. Journal of Experimental Psychology: Learning, Memory, \& Cognition, 24, 1005-1025.

Shallice, T., Fletcher, P., Frith, C. D., Grasby, P., Frackowiak, R. S. J., \& Dolan, R. J. (1994). Brain regions associated with acquisition and retrieval of verbal episodic memory. Nature, 368, 633-635.

SMITH, E. E., \& JoNIDES, J. (1999). Storage and executive processes in the frontal lobes. Science, 283, 1657-1661.

SNODGRass, J. G., \& VANDERWART, M. (1980). A standardized set of 260 pictures: Norms for name agreement, image agreement, familiarity, and visual complexity. Journal of Experimental Psychology: Human Learning \& Memory, 6, 174-215.

STUSs, D. T., \& BENSON, D. F. (1986). The frontal lobes. New York: Raven

TAlairach, J., \& Tournoux, P. (1988). Co-planar stereotaxic atlas of the human brain. New York: Thieme.

Tulving, E., Kapur, S., Craik, F. I. M., Moscovitch, M., \& Houle, S. (1994). Hemispheric encoding/retrieval asymmetry in episodic memory: Positron emission tomography findings. Proceedings of the $\mathrm{Na}$ tional Academy of Sciences, 91, 2016-2020.

Tulving, E., Markowitsch, H. J., Craik, F. I. M., Habib, R., \& HouLE, S. (1996). Novelty and familiarity activations in PET studies of memory encoding and retrieval. Cerebral Cortex, 6, 71-79.

Vandenberghe, R., Duncan, J., Dupont, P., Ward, R., Poline, J. Bormans, G., Michiels, J., Mortelmans, L., \& Orban, G. A. (1997). Attention to one or two features in left or right visual field: A positron emission tomography study. Journal of Neuroscience, 17 3739-3750.

VAN KLEECK, M. H. (1989). Hemispheric differences in global versus local processing of hierarchical visual stimuli by normal subjects: New data and a meta-analysis of previous studies. Neuropsychologia, 27, 1165-1178

Wagner, A. D., Poldrack, R. A., Eldridge, L. L., Desmond, J. E. Glover, G. H., \& GABRIELI, J. D. E. (1998). Material-specific lateralization of prefrontal activation during episodic encoding and retrieval. NeuroReport, 9, 3711-3717.

Woods, R. P., Cherry, S. R., \& Mazziotta, J. C. (1992). Rapid automated algorithm for aligning and reslicing PET images. Journal of Computer Assisted Tomography, 16, 620-633.

(Manuscript received October 27, 1999; revision accepted for publication April 6, 2000.) 